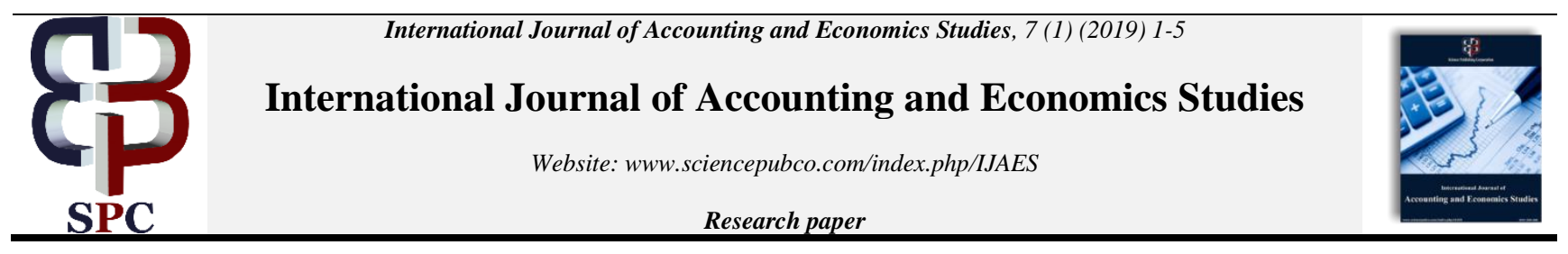

\title{
Socio-economic correlates of more than one personal account ownership in the Kumasi Metropolis of Ghana
}

\author{
Jonas Bawuah $^{1,2}{ }^{*}$, Kong Yusheng ${ }^{1}$, Isaac K. Jerry Asare ${ }^{1}$, Stella Osei Owusu ${ }^{3}$ \\ ${ }^{1}$ School of Finance and Economics, Jiangsu University, 301 Xuefu Rd. Zhenjiang, Jiangsu 212013 P.R. China \\ ${ }^{2}$ Department of Accountancy and Accounting Information Systems, Kumasi Technical University, \\ P. O. BOX 854 Kumasi-Ghana \\ ${ }^{3}$ Zenith Bank (Ghana) Limited. PMB CT393, Accra- Ghana \\ *Corresponding authorE-mail:jonas.bawuah@gmail.com
}

\begin{abstract}
Financial inclusion is seen as one of the major tools that can be used to oust poverty. Given this, several studies have been done to find out the kind of individuals who are likely to have indicators of financial inclusion such as ownership of savings accounts among others. However, it has been observed that certain individuals tend to have multiple savings accounts in which very little is known in the literature about the features of such individuals and why. This study therefore purposively sampled 200 adult respondents in the Kumasi Metropolis of Ghana with at least one account in any formal institution, in order to investigate the determinants of more than one or multiple personal financial accounts holding. The study employed the binary logit model as the empirical estimation technique. The study therefore found that, most respondents chose enjoyment of several benefits as the most important reason they own more than one personal account. From the regression estimates, the study revealed males, those aged 31-40 years, the employed, married, respondents with junior high school (J.H.S), senior high school (S.H.S) and tertiary levels of education to be more likely to own more than one personal account. The findings therefore fill a major gap in the financial inclusion literature and hence further reinforce the essence of socio-economic factors such as gender, age, education, employment, religion and marital status in the financial inclusion drive.
\end{abstract}

Keywords: Financial Inclusion; More Than One or Multiple Accounts Ownership; Ghana.

\section{Introduction}

Globally there are challenges with access to comfortable accommodation, proper sanitation and hygiene, quality health care, food and clothing, which all could be attributed to the extreme poverty experienced by most people in the world especially in developing countries. Thus, poverty tends to affect total well-being of individuals which has implications on mortality rates and hence sustainable development. According to the United Nations (UN), 836 million people still wallow in extreme poverty and about 1 in every 5 people in developing countries live below $\$ 1.25$ per day, with most of these people living in sub Saharan Africa and Southern Asia (accessed from: http://www.un.org/sustainabledevelopment/poverty/ on 14/07/2017). It is therefore not surprising that, eradicating poverty is the number one goal among the seventeen sustainable development goals (SGDS) to be achieved by 2030.

However, one of the major solutions offered to handle poverty is financial inclusion, thus making funds easily accessible to the less disadvantaged in society. Therefore, ownership of accounts, accesses to credit among others are all considered to be indicators of financial inclusion. This has therefore necessitated studies on financial inclusion globally.

In Ghana, the story has not been different since according to the Ghana Living Standards Survey Round 6 (GLSS6), one-fourth of Ghanaians are poor, with a tenth of the population living under extreme poverty (Ghana Statistical Service [GSS], 2014). Given the effectiveness of financial inclusion in eradicating poverty, however surprisingly, according to the World Bank as cited in (Segbefia, 2015), 70\% of the Ghanaian population is considered to be unbanked. It is therefore not surprising that some studies have been done on the determinants of financial inclusion in Ghana, even though the author contends that these studies are too few given the nature of the poverty challenge in Ghana and hence necessitating more studies on the subject matter. In addition, a careful study of the literature has shown that attention has just being on the determinants of ownership of accounts with little attention paid to the determinants of more than one account ownership in Ghana. Thus, this study proposes to widen the dimensions of the financial inclusion literature and hence filling a major gap in the literature by providing a response to who among formal account owners, are the holders of multiple accounts in the Kumasi Metropolis of Ghana to be precise.

This would further provide insights to policy makers and stake holders on who should be targeted in the attempt to further reinvigorate financial inclusion in Ghana. 


\section{Literature review}

With poverty being a global challenge, several strategies have been adopted to quell poverty and among these is financial inclusion. Financial inclusion simply has to do with attempts geared at making the vulnerable in society get access to funding which end-up bettering their shelter, accommodation, health, education, food, hygiene and sanitation and hence an improvement in their total welfare. Thus financial inclusion is seen as one of the effective tools of ensuring economic growth and development. Based on the above, several studies have been done globally on factors that influence proxies of financial institution such as ownership of accounts, access to credit e.t.c.

Form the utility maximisation theory, a person may choose to own more than one account or not depending on the expected utility. Thus if the expected utility of owning more than one account is higher than the expected utility of not owning, the person would opt to own more than one account and if otherwise, would not opt to own.

Empirically, Mutandwa and Kwiringirimana (2015), Muturi and Wairegi (2015) and Aregbeyen (2011) have investigated the factors that influence the choice of financial institution in Rwanda, Kenya and Nigeria respectively. Zins and Weill (2016) in thirty seven African countries found that being older, a man, more educated and richer, ensures financial inclusion. Efobi, Beecroft and Osabuohien (2014) in Nigeria found income level, age among others to influence the access and use of bank services. Allen, Demirguc-Kunt, Klapper and Peria (2012) studied the ownership and usage of accounts in 123 countries.

On Ghana Atuahene, Adarkwa, Donkor and Darko (2017) found that Christians, respondents who were 51-60 years, those with secondary, basic and tertiary levels of education, those married, the employed, and respondents with no proximity challenges to the nearest financial institution to be more likely to own accounts. Darko, Adarkwa and Donkor (2017) also have investigated the personal features of individuals and how they influence the choice of financial institution. Agyekum, Wellalage and Locke (n.d) used credit advanced to the private sector to study financial inclusion in Ghana. Boakye and Amankwah (n.d) have investigated factors that influence the demand for financial products in Ghana. Akudugu (2013) found age, wealth class, distance to financial institutions, literacy levels, among others to influence financial inclusion in Ghana. Davidson (2011), Hinson, Osarenkhoe and Okoe (2013), Abbam, Dadson and Say (2015) and Abbam, Say and Carsamer (2015) have investigated the factors that influence the choice of financial institution in Ghana.

However, with regards to the works above, precisely those on Ghana, aside the paucity of research on the determinants of financial inclusion, no study to the best of the author's knowledge has investigated the features of those who own more than one or multiple personal accounts in formal financial institutions in Ghana. Thus, no study to the best of the author's knowledge has provided a response to the question, who are the users of multiple personal accounts among account holders in Ghana? Thus this study fills a major research gap in the financial inclusion literature by drawing policy makers' attention to how the socio-economic features of individuals influence them to own more than one personal account.

\section{Methods}

This study was conducted in the Kumasi Metropolis of Ghana. The setting was chosen because of its heterogeneous nature and hence having a collection of the people from all the various parts of the country. Thus 200 respondents who were 18 years and above and had at least one personal account with any formal financial institution were purposively sampled in early to late June 2018, and the questionnaires of the study were administered to them. Thus, the questionnaire contained information on whether respondents had more than one personal accounts with different or the same formal financial institution or not. Thus, having more than one personal account was what the study was interested in. In addition, other socio-economic and demographic features of respondents were captured. Thus, the study used primary data in the form of questionnaires as the main source of data.

Hence the main financial inclusion proxy used by the study was either having more than one personal account or not (one formal account). Therefore, if a respondent answered yes, it was coded as 1 and if a respondent answered no, it was coded as 0 . Hence given that the dependent variable of the study (ownership of more than one personal account) was binary, the study employed the binary logit model as the empirical estimation technique. It must be stated that in this study, multiple accounts ownership is used interchangeably with more than one account ownership

Further since the explanatory variables of the study i.e. gender, age, education, employment, religion and marital status were categorical; the study treated them as dummy variables. It must further be stated that all the data analyses in this study were done using stata 14.0 statistical package.

\section{Results and discussion}

Table 1: Descriptive Statistics of Multiple Accounts Ownership

\begin{tabular}{lll}
\hline Variable & Frequency & Percentage \\
\hline Ownership of more than One (Multiple) Financial Accounts & 122 & 61.00 \\
No & 78 & 39.00 \\
Yes & $\mathrm{N}=200$ & Total=100\% \\
& & 34.62 \\
Most Important Reason for Holding Multiple Personal Financial Accounts & 27 & 42.31 \\
For several/different needs & 33 & 15.38 \\
To enjoy multiple benefits & 12 & 7.69 \\
Fear of collapse of financial institution & 6 & $\mathrm{~T}$ \\
Indecisiveness & $\mathrm{N}=78$ & Total=100\% \\
\hline
\end{tabular}

Source: Authors computation from Field survey, 2018.

From Table 1, it can been seen that out of the 200 respondents, 122 representing $61 \%$ did not have more than one (multiple) personal financial accounts whiles 78 of them representing $39 \%$ had multiple accounts. Thus majority of the respondents did not have multiple personal financial accounts. Considering the most important reason for having multiple accounts (i.e among the 78 respondents who had multiple accounts), 27 of the respondents representing $34.62 \%$ said they have multiple accounts with the purpose of assigning each account to a particular item/ item(s) they want to satisfy. Also 33 of them constituting $42.31 \%$ said they own more than one/ multiple accounts in order to reap the different benefits offered by the same or different financial institution. Further, 12 of the respondents representing $15.38 \%$ said they own multiple accounts because of the fear that some or one of the financial institutions may collapse whiles 6 of the respondents 
said they chose to have multiple accounts with different banks/financial institutions because they were not sure (Indecisive) as to the quality and attractiveness of the services provided by the financial institutions. Thus, from this study, the quest to enjoy multiple benefits is the main reason why people choose to have more than one financial accounts.

Table 2: Bivariate Analyses of Socio-Economic Factors and Multiple Personal Financial Accounts Ownership

\begin{tabular}{|c|c|c|c|}
\hline \multirow[t]{2}{*}{ Variable } & \multicolumn{2}{|c|}{ Ownership of Multiple Accounts } & \multirow[t]{2}{*}{ Chi Square Test } \\
\hline & No $(\%)$ & Yes $(\%)$ & \\
\hline Gender & & & $83.3170 * * *$ \\
\hline Male & 25.84 & 74.16 & \\
\hline Female & 89.19 & 10.81 & \\
\hline Religion & & & $64.3598 * * *$ \\
\hline Christianity & 30.68 & 69.32 & \\
\hline Islam & 77.61 & 22.39 & \\
\hline Traditional/other/no religion & 95.56 & 4.44 & \\
\hline Educational Level & & & $133.1522 * * *$ \\
\hline Uneducated & 96.67 & 3.33 & \\
\hline Primary & 84.62 & 15.38 & \\
\hline Junior High School(JHS) & 36.36 & 63.64 & \\
\hline Senior High School (SHS) & 10.81 & 89.19 & \\
\hline Tertiary & 4.00 & 96.00 & \\
\hline Respondent's Age & & & $82.9147 * * *$ \\
\hline $18-30$ years & 86.96 & 13.04 & \\
\hline $31-40$ years & 18.33 & 81.67 & \\
\hline 41-50 years & 45.83 & 54.17 & \\
\hline $51-60$ years & 72.41 & 27.59 & \\
\hline 61years and above & 95.12 & 4.88 & \\
\hline Employment Status & & & $53.3081 * * *$ \\
\hline Employed & 35.05 & 64.95 & \\
\hline Unemployed & 85.44 & 14.56 & \\
\hline Marital Status & & & $78.7781 * * *$ \\
\hline single/widowed/divorced/separated & 91.92 & 8.08 & \\
\hline Married & 30.69 & 69.31 & \\
\hline
\end{tabular}

The bivariate analyses using the Pearson chi square showed that, gender, religion, education, age, employment and marital status had statistically significant relationships with ownership of multiple accounts. Further it can be seen that, among the male respondents, $74.16 \%$ had multiple personal financial accounts whiles among the females only $10.81 \%$ had. Also among the Christians, Muslims and Traditional/other/no religion believers, $69.32 \%, 22.39 \%$ and $4.44 \%$ had multiple personal financial accounts respectively. Concerning the education of respondents and multiple personal financial accounts ownership, it can be seen that among respondents with no education, primary education, Junior High School (JHS) level of education, Senior High School (SHS) level of education and Tertiary level of education, $3.33 \%, 15.38 \%, 63.64 \%, 89.19 \%$ and $96.00 \%$ had multiple personal financial accounts respectively. The result on education showed a rise in the level of education being linked with the ownership of multiple personal financial accounts.

Also $13.04 \%, 81.67 \%, 54.17 \%, 27.59 \%$ and $4.88 \%$ among responds with ages 18-30 years, 31-40 years, $41-50$ years, 51-60 years and 60 years and above had multiple personal financial accounts respectively. Thus majority of respondents who were 31-40 years and 41-50 years had multiple personal financial accounts.

In addition among the employed respondents, $64.95 \%$ had multiple personal financial accounts whiles among the unemployed, $14.56 \%$ had multiple personal financial accounts. Thus more of the employed had multiple personal financial accounts than the unemployed.

Concerning marital status, it can be seen that among those who were single/widowed/divorced/separated, only $8.08 \%$ of them had multiple personal financial accounts whiles among the married respondents, $69.31 \%$ had multiple personal financial accounts.

Given that the bivariate analyses did not control for other variables that could influence ownership of more than one or multiple accounts but dealt with only two variables, we further employed a multivariate logistic regression in order to control for other variables as shown in Table 3.0 below.

Table 3: Logit Regression Results on Determinants of Multiple Personal Financial Accounts Ownership

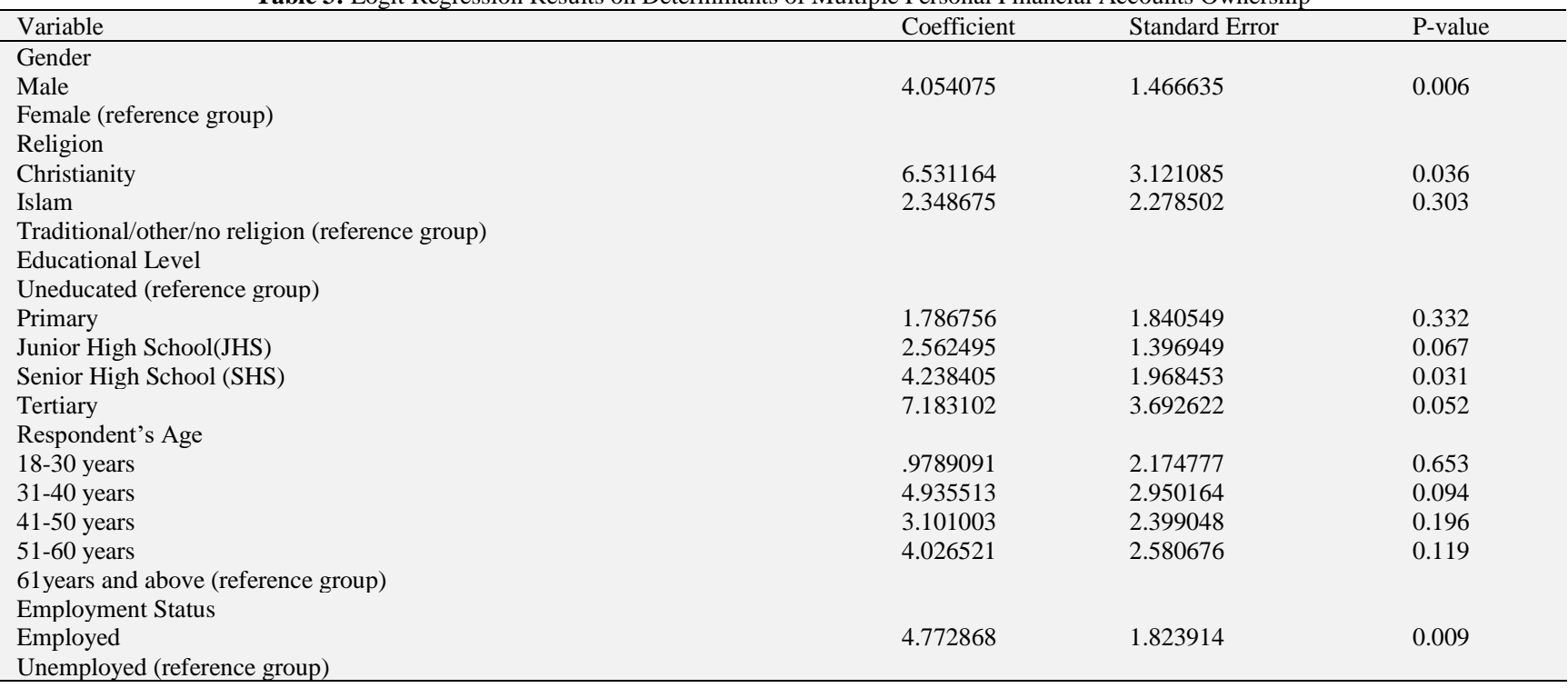




\begin{tabular}{lll} 
Marital Status & & \\
single/widowed/divorced/separated (reference group) & 4.127804 & 1.800148 \\
Married & -17.96322 & 0.022 \\
Constant & 0.770872 & 008 \\
\hline
\end{tabular}

Source: Authors' Computation from Field Survey, 2018. Number of Obs =200; Prob > Chi2 $=0.0000$

From the logit results, it can be seen that male respondents were found to be more likely to own multiple (more than one) personal accounts as compared to female respondents. This is because male had a positive coefficient which was significant at $1 \%$ given that its $\mathrm{p}$-value of 0.006 was below 0.01 . This could be that since males are more likely to be the breadwinners of various families, they might want to have more than one personal financial accounts in order to cushion themselves in case one financial institution collapses, or to save to satisfy specific needs or better still to enjoy the benefits provided by different or the same financial institutions.

Also, since Christianity had a positive coefficient of 6.531164 that was significant at 5\%, it implied that, Christians were more likely to own more than one accounts relative to Traditional/other/no religion respondents.

In addition given that respondents with JHS, SHS and Tertiary levels of education had positive coefficients of $2.562495,4.238405$ and 7.183102 that were significant at $10 \%, 5 \%$ and $10 \%$ respectively, the implication is that respondents with JHS, SHS and Tertiary levels of education were more likely to own more than one personal financial account relative to their uneducated counterparts. This is not startling since the educated can better comprehend the essence of having more than one financial accounts given its attendant benefits relative to the uneducated.

Further, respondents who were 31-40 years were found to be more likely to own more than one personal financial account relative to their counterparts who were 60 years and above. This is because its coefficient of 4.935513 was significant at $10 \%$.

Moreover, respondents who were employed were found to be more likely to own multiple accounts relative to those who were unemployed. This is because of the positive coefficient of 4.772868 for employed respondent that was significant at $1 \%$. This finding is not surprising since the employed are more likely to earn than the unemployed and hence would be more capable of owning multiple accounts relative to the unemployed.

Last but not the least, married respondents were found to be more likely to have more than one financial account relative to their single/widowed/divorced/separated counterparts. Thus it could be that since married individuals are more likely to have more needs to satisfy, they would rather be willing to have more than one financial account in order to cushion themselves in case one financial institution collapses, or to save in more than one financial institution to satisfy specific needs or better still to enjoy the benefits provided by different or same financial institution.

\section{Conclusion}

Based on the findings, it can be concluded that, socio-economic factors such as gender, age, education, employment, religion and marital status are relevant determinants of multiple account ownership among formal account holders and hence must be blended with the findings of other studies on financial inclusion in order to come out robust multifaceted policies geared towards enhancing financial inclusion.

\section{Acknowledgement}

This paper is supported by National Natural Science Foundation of China. Number 71371087 The authors are grateful to all the individuals who aided in the data collection

\section{References}

[1] Abbam, A., Dadson, I., \& Say, J. (2015). An Empirical Analysis of Customer Choice of Banks in Ghana. European Journal of Business and Management, 7(12).

[2] Abbam, A., Say, J., \& Carsamer, E. (2015). An Analysis of Choice of Commercial Banks among University students in Ghana. International Journal of Economics, Commerce and Management,3(2).

[3] Agyekum, F.K., Wellalage, N.H. and Locke, S. (n.d). Financial Inclusion in Ghana; does Institutional Context Matter?

[4] Akudugu. M.A. (2013). The Determinants of Financial Inclusion in Western Africa: Insights from Ghana. Research Journal of Finance and Accounting 4(8).

[5] Allen, F., Demirguc-Kunt, A., Klapper, L., \& Peria, M.S.M. (2012). The Foundations of Financial Inclusion: Understanding Ownership and Use of Formal Accounts. The World Bank, Development Research Group, Finance and Private Sector Development Team, Policy Research Working Paper 6290 https://doi.org/10.1596/1813-9450-6290.

[6] Aregbeyen, O. (2011). The Determinants of Bank Selection Choices by Customers: Recent and Extensive Evidence from Nigeria, International Journal of Business and Social Science,2(22).

[7] Atuahene, S.S.O, Adarkwa, S, Donkor, F. \& Darko, E.A. (2017). Determinants of Financial Inclusion in a Developing Economy: Evidence from the Asokore Mampong Municipality of Ghana. The International Journal of Business \& Management,5(4).

[8] Boakye, C. \& Amankwah, N. O. A (n.d). Determinants of the demand for financial Products in Ghana.

[9] Darko, E. A., Adarkwa, S. \& Donkor, F. (2017). Individual Characteristics of Customers and the Choice of Financial Institution in Ghana: A Multinomial Probit Regression Approach. European Journal of Business Economics and Accountancy, 5(3). European.

[10] Davidson, A-A (2011). The factors that influence the choice of banks by customers - A case study of Makola community. Master's Thesis, Institute of Distance Learning, Kwame Nkrumah University of Science and Technology, Ghana.

[11] Efobi, U., Beecroft, I., \& Osabuohien, E. (2014). Access to and use of bank services in Nigeria: Micro-econometric evidence. Review of Development Finance, 4, 104-114. https://doi.org/10.1016/j.rdf.2014.05.002.

[12] Ghana Statistical Service. (2014). The Ghana Living Standards Survey Round 6, Poverty Profile in Ghana (2005-2013).

[13] Hinson, R.E.., Osarenkhoe, A., \& Okoe, A.F. (2013). Determinants of Bank Selection: A Study of Undergraduate Students in the University of Ghana. Journal of Service Science and Management, 6, 197-205. https://doi.org/10.4236/jssm.2013.63021.

[14] Mutandwa, E., \& Kwiringirimana, T. (2015). Factors affecting choice of financial services among rural consumers: Emerging experiences from Gicumbi District, northern Province in Rwanda. Journal of Agriculture and Rural Development in the Tropics and Subtropics $116(2), 187-197$.

[15] Muturi, W., \& Wairegi, H. (2015). Determinants of Choice of Financial Institutions for Transport Entrepreneurs in KISII County. The International Journal of Business \& Management, 3(7). 
[16] Segbefia, L. (2015). 70\% Of Ghana's Population Is Unbanked. Accessed from: https://www.newsghana.com.gh/70-of-ghanas-population-is-unbanked/ on 14/07/2017.

[17] United Nations (n.d). Sustainable Development Goals: 17 Goals to transform our world. Accessed: from: http://www.un.org/sustainabledevelopment/poverty/ on 14/07/2017.

[18] Zins, A, \& Weill, L. (2016). The determinants of financial inclusion in Africa. Review of Development Finance, 6, 46-57. https://doi.org/10.1016/j.rdf.2016.05.001. 